\title{
Rock Magnetism of Remagnetized Paleozoic Carbonates: Low-Temperature Behavior and Susceptibility Characteristics
}

\author{
MIKE JACKSON, ${ }^{1}$ AND PIERRE ROCHETTE \\ Laboratoire de Geophysique Inteme et Tectonophysique, Université Joseph Fourier, Grenoble, France
}

\author{
GÉRARD FILLION
}

Laboratoire Louis Néel, Centre Nationale de la Récherche Scientifique, Grenoble, France

\author{
SUBIR BANERJEE AND JIM MARVIN
}

Institute for Rock Magnetism, Department of Geology and Geophysics, University of Minnesota, Minneapolis

\begin{abstract}
We have conducted a new set of rock magnetic experiments on samples of remagnetized Paleozoic carbonates of eastern North America. These experiments were designed to investigate the origin of the unusual hysteresis behavior of these rocks, by evaluating (1) the importance of ferrimagnetic pyrthotite as a remanence carrier, and (2) the sources of low-field susceptibility. Low-temperature measurements of saturation isothermal remanent magnetization (SIRM) indicate that the pyrrhotite magnetic transition at $32 \mathrm{~K}$ is absent in the Trenton and Onondaga limestones of New York. This transition is observed but poorly expressed in the Knox Group of east Tennessee: room-temperature SIRMs, cooled to $10 \mathrm{~K}$ in zero field, lose a small fraction of their intensity between 30 and $35 \mathrm{~K}$. Samples from all three formations show a broad peak in IRM intensity at about $200 \mathrm{~K}$, which is typical of pyrrhotite. In the Trenton and Onondaga samples, the ferrimagnetic component of low-field susceptibility is significantly larger than the ratio $M_{r s} / H_{c r}$, and is thus probably due dominantly to magnetite; in some of the Knox samples the reverse is true, suggesting an important pynhotite contribution. For all of the samples, the ferrimagnetic susceptibility, normalized by the saturation magnetization, is anomalously high, about a factor of 5 or 10 higher than the typical value for magnetite. We believe that this indicates a very substantial contribution from superparamagnetic particles. Strong frequency dependence of susceptibility and very high ratios of anhysteretic to saturation remanence confirm the importance of ultrafine particles, spanning the superparamagnetic-single-domain boundary. All three of these chemically remagnetized carbonates units exhibit the following properties, which have not previously been found together for any rock or synthetic analog, and which therefore appear to constitute a diagnostic set of rockmagnetic criteria for recognizing chemically-remagnetized rocks: $M_{r s} J M_{s} \approx 0.89\left(H_{c r} / H_{c}\right)^{-0.6} ; k_{f} / M_{s} \approx 50 \mu \mathrm{m} / \mathrm{A} ;$ ARM/SIRM $\approx 20 \% ; k_{d} /\left(M_{r s} / H_{c r}\right) \approx 50$.
\end{abstract}

\section{INTRODUCTION}

The Paleozoic strata of eastern and central North America, particularly the carbonate units, were extensively remagnetized during the late Paleozoic Kiaman reverse geomagnetic polarity superchron, and abundant evidence now points to a mechanism involving growth of new magnetite by authigenic precipitation and/or by alteration of preexisting sulfides, especially pyrite [McCabe and Elmore, 1989; Van der Voo, 1989; Suk et al., 1990a, $b$; Lu et al., 1990]. Previous rockmagnetic studies on these remagnetized carbonates have indicated a predominance of fine ferrimagnetic particle sizes (single domain to pseudo-single domain, SD to PSD), and suggested a dominantly cubic (magnetocrystalline) anisotropy [Jackson, 1990a]. These inferences were based mainly on hysteresis properties, which are characterized by an unusual combination of relatively high ratios

\footnotetext{
1 Now at Institute for Rock Magnetism, Department of Geology and Geophysics, University of Minnesota, Minneapolis.
}

Copyright 1993 by the American Geophysical Union.

Paper number 92JB01319.

0148-0227/93/92JB-01319\$05.00 of saturation remanence to saturation magnetization $\left(M_{r s} / M_{s}\right)$ and remanent to bulk coercivity $\left(H_{c r} / H_{c}\right)$ [Jackson, 1990a].

In this study we investigate a possible alternative explanation for the unusually high values of these two hysteresis ratios, namely an unrecognized and significant contribution from ferrimagnetic pyrnhotite. Although it is clear that pyrrhotite is not responsible for the characteristic late Paleozoic natural remanent magnetization (NRM) of these rocks (which unblocks at temperatures above the Curie temperature of pyrrhotite, about $325^{\circ} \mathrm{C}$ ), there are several reasons to suspect that pyrrhotite may be partially responsible for their unusual bulk magnetic properties. First, Freeman [1986] reported abundant ferrimagnetic pyrrhotite in magnetic extracts from the Helderberg limestone, despite the fact that Scotese et al. [1982] saw evidence of only pure magnetite in their thermomagnetic analysis of Helderberg extracts. Second, the coexistence of pyrrhotite with magnetite is not easily recognized by the use of such common techniques as acquisition and thermal demagnetization of isothermal remanent magnetization (IRM) [e.g., Lowrie and Heller, 1982]. Although there is not a well-defined inflection in IRM decay curves from these carbonates, there is inevitably a large fraction (roughly $75 \%$ ) of saturation isothermal remanent magnetization (SIRM) removed by heating to $300^{\circ}-325^{\circ} \mathrm{C}$ [Kent, 1979; Stead and Kodama, 1984]. Third, hysteresis ratios very similar to those of the remagnetized 
carbonates have been measured for synthetic magnetite-hematite mixtures [Jackson et al., 1990]; it is conceivable that magnetitepyrrhotite mixtures may exhibit similar behavior, due to the high $M_{r s} M_{s}$ ratios and moderately high coercivities typical of pyrrhotite [Dekkers, 1988; Clark, 1984]. Like hematite, pyrrhotite has an easy magnetic plane and a hard axis, and very high anisotropy. Finally, recent low-temperature studies have shown that ferrimagnetic pyrrhotite may be much more common in a variety of rock types (including Appalachian Paleozoic carbonates) than is generally recognized [Rochette et al., 1990].

In addition to testing for a significant ferrimagnetic pyrrhotite contribution to the magnetic properties of these carbonates, we examine their susceptibility characteristics, including frequency dependence, in some detail. This provides additional evidence bearing on the ferrimagnetic mineralogy and grain size distribution.

\section{METHODS}

Probably the most definitive means of identifying ferrimagnetic pyrrhotite in magnetite-bearing rocks is by its magnetic transition at $32 \mathrm{~K}$ [Rochette et al., 1990; Dekkers et al., 1989]. This method is preferable to thermomagnetic analysis for several reasons. First, any significant magnetic changes at this temperature can be attributed unambiguously to pyrrhotite; in contrast, Curie temperatures near $325^{\circ} \mathrm{C}$ may be due to titanium-bearing magnetites or hematites. Further, because the ratio $M_{r s} / M_{s}$ is typically much higher for pyrrhotites than for magnetites [Dekkers, 1988], pyrrhotite may be an important source of remanence while contributing insignificantly to $M_{S}$ in magnetite-bearing rocks, rendering it "invisible" in high-field thermomagnetic studies. Additionally, when using a high-sensitivity, low-temperature superconducting quantum interference device (SQUID), it is possible to analyze whole-rock samples rather than extracts, which may not be truly representative of the magnetic sources in the rock. And finally, the degree of recovery on rewarming through the transition temperature provides important grain size information [Dekkers et al., 1989].

Additional characteristic properties for distinguishing magnetite and pyrrhotite are based on the relationship between ferrimagnetic susceptibility $\left(k_{f}\right)$ and various other rockmagnetic parameters. Worm [1991] reports that for pyrrhotite $k_{f}$ is much smaller than the self-demagnetization limit $1 / N$, where $N$ is the demagnetizing factor (measured susceptibility is related to intrinsic susceptibility $\mathrm{k}_{\mathrm{i}}$ by $1 / k_{f}=1 / \mathrm{k}_{\mathrm{i}}+\mathrm{N}$; thus for large $\left.\mathrm{k}_{\mathrm{i}}, k_{f} \approx 1 / \mathrm{N}\right)$. Worm [1991] has also demonstrated that $k_{f}$ in pyrrhotite is strongly field-dependent. For magnetite, $k_{f}$ is much larger than the ratio $M_{r s} / H_{c r}$ for pyrrhotite it is considerably smaller than this ratio [Dekkers, 1988]. Similarly, a comparison of the data of Dekkers [1988] for pyrrhotite with that compiled by Maher [1988] for magnetite indicates that the ratio $k_{f} / M_{s}$ is typically lower for pyrrhotite than for magnetite, by about a factor of 2 . Anhysteretic remanent magnetization (ARM), normalized by direct field strength, may be referred to as anhysteretic susceptibility $k_{a}$ [King et al., 1982]. The ratio $k_{a} / k_{f}$ is typically much larger for pyrrhotite than for magnetite [Rochette, 1988].

In this study we have investigated these properties, as well as the frequency-dependence of susceptibility, for approximately $\mathbf{4 0}$ samples of the Trenton limestone (Ordovician, New York), Onondaga limestone (Devonian, New York), and Knox Dolomite (Ordovician, Tennessee). These samples have been used in a number of previous studies of paleomagnetism [McCabe et al., 1984; Bachtadse et al., 1987], anisotropy [McCabe et al., 1985; Jackson et al., 1989; Jackson, 1990b], and rock magnetism
[McCabe et al., 1989; Jackson, 1990a]. We have used three different sets of specimens for a combination of non-destructive and destructive (e.g., heating or extraction) experiments. Saturation magnetization and paramagnetic susceptibility $k_{p}$ were determined from high-field hysteresis measurements; the low-field ferrimagnetic susceptibility $k_{f}$ was determined by subtracting $k_{p}$ from the previously-measured low-field susceptibility $k_{o}$.

For a few samples, the room-temperature SIRM acquired during the high-field measurements was then cooled to 5 or $10 \mathrm{~K}$ in zero field in $10^{\circ}$ or $20^{\circ}$ steps, using a SHE Corporation SQUID susceptometer in the Néel laboratory in Grenoble. Lowtemperature measurements for two additional samples were made with a Quantum Design Magnetic Property Measurement System (MPMS) at the University of Minnesota. The "zero field" control of these instruments is somewhat loose, and actual fields may have been as large as a few hundred microtesla. As a result, a paramagnetic correction had to be applied to the low-temperature data (since the induced paramagnetic magnetization varies inversely with temperature, it became quite large in a few cases).

Other samples were thermally demagnetized after the high-field measurements, or crushed for preparation of magnetic extracts. Frequency-dependent susceptibility was measured with a Bartington dual-frequency alternating current bridge (470 and $4700 \mathrm{~Hz}$ ). Due to the effects of high-field treatment on susceptibility [e.g., Potter and Stephenson, 1990] these measurements were made on specimens that had not been used for hysteresis measurements. Additional low-frequency susceptibility measurements were made with a Kappabridge KLY-2 instrument in Grenoble. Anhysteretic remanence was imparted with a Schonstedt alternating field demagnetizer with a peak amplitude of $100 \mathrm{mT}$ and a superimposed steady field of $100 \mathrm{mT}$.

\section{RESULTS}

Thermal demagnetization of SIRM shows unblocking temperatures almost entirely below $400^{\circ}$ or $450^{\circ} \mathrm{C}$, and at least $70 \%$ removed by $350^{\circ} \mathrm{C}$, as shown previously by Kent [1979] and by Stead and Kodama [1984] (Figure 1). Although it is not well defined, there is a suggestion of an inflection in many of the curves at about the Curie temperature of pyrrhotite, suggesting but not requiring an important contribution from that mineral. Kent [1985] interpreted the thermal demagnetization behavior as indicating predominantly multidomain magnetite, because the unblocking temperatures are so far below the Curie temperature for pure magnetite. More generally, the unblocking behavior can be interpreted as arising from magnetite dominated by magnetocrystalline anisotropy, as the demagnetization curves closely mirror the temperature dependence of the cubic anisotropy constant $\mathrm{K}_{1}$ [e.g., O'Reilly, 1984].

The pyrrhotite low-temperature transition is either poorly defined or completely absent in all of the samples analyzed (Figure 2). Only one sample of the Knox dolomite shows an observable loss of remanence on cooling below $50 \mathrm{~K}$. The apparent transition temperature is slightly higher than expected, probably because of an "undershoot" in the temperature stepping. On rewarming through the transition temperature, this sample shows no recovery. This is unlike any of the types of transition behavior described by Dekkers et al. [1989] for natural and synthetic pyrrhotites of various grain sizes, all of which exhibited at least $50 \%$ recovery, with almost perfect reversibility of the transition for the finest grain sizes. In contrast, the magnetite low-temperature transition [Verwey and Haayman, 1941; Nagata et al., 1964; Chikazumi, 1975; Dunlop and Argyle, 1991] at approximately $120 \mathrm{~K}$ is clearly defined in two of the samples (Figure 2). Thus the low- 


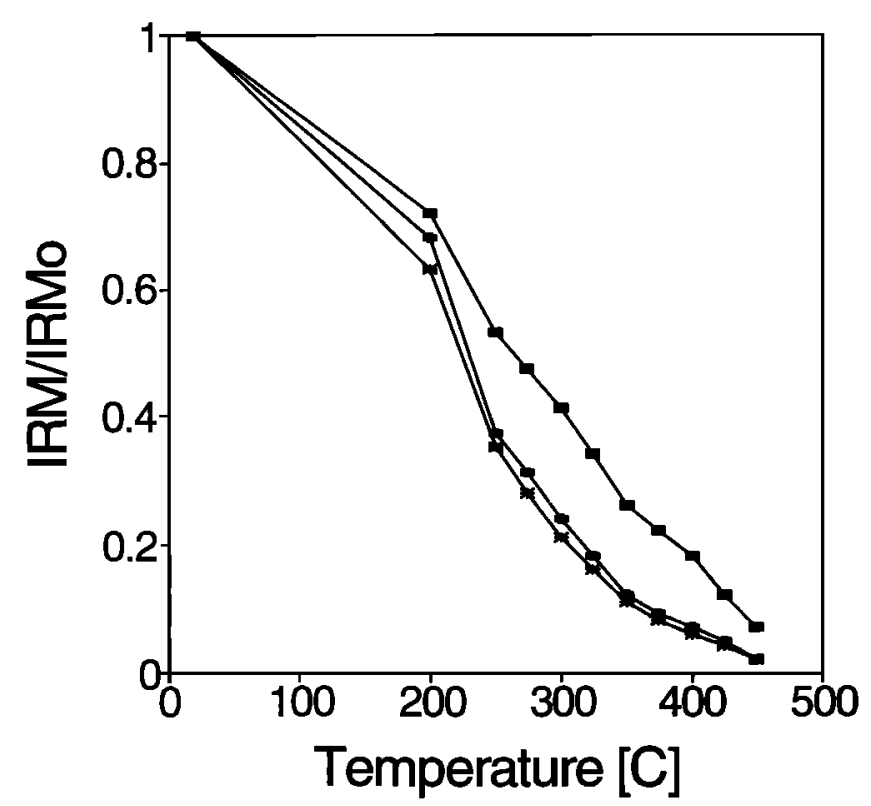

Fig. 1. Decay of saturation remanence during stepwise thermal demagnetization, for three typical samples (Onondaga, plusses; Trenton, asterisks; and Knox, squares).

temperature behavior of room temperature IRM does not appear to indicate a significant pyrrhotite contribution in most samples.

Interestingly, however, almost all samples show a fairly well defined, broad peak in IRM intensity at about $200 \mathrm{~K}$, with values $5 \%$ to $10 \%$ higher than room temperature values. Dekkers [1989] finds that this is typical of well-characterized natural pyrrhotites of a wide range of grain sizes. Increasing intensity of SIRM on cooling in zero field undoubtedly arises from increasing spontaneous magnetization; this can be expected to occur for both magnetite and pyrrhotite, but with a stronger temperature dependence for the latter by virtue of its lower $T_{c}$. However, the decrease in intensity on further cooling below $200 \mathrm{~K}$ seems to indicate a reduction in spontaneous magnetization, i.e., the behavior of a P-type ferrite. Such a decrease is not expected to occur in magnetite due to the nature of the interactions in that mineral [Stacey and Banerjee, 1974], nor is it generally observed experimentally in magnetite-bearing carbonate rocks [e.g., Lowrie and Heller, 1982]. Dekkers' [1989] measurements on pyrrhotites, on the other hand, show a maximum in $M_{s}$ at the same temperature, and he points out that this correlates with changes in the anisotropy constants for pyrrhotite; in particular, $\mathbf{K}_{3}$ changes sign and $\mathrm{K}_{4}$ has a maximum at $205 \mathrm{~K}$ [Bin and Pauthenet, 1963]. Thus the low-temperature data are suggestive of some contribution from pyrrhotite, but the lack of a transition at $32 \mathrm{~K}$ is problematic.

Table 1 summarizes the low- and high-field susceptibility data. Ferrimagnetic susceptibility on average constitutes about $75 \%$ of the overall $\mathrm{k}_{\mathrm{o}}$, but the proportion is quite variable, ranging from about $30 \%$ to essentially $100 \%$, with values between $10^{-5}$ and $10^{-4}$ SI volume-normalized units. The ratio $M_{r s} / H_{c r}$ ranges from about $10^{-6}$ to $10^{-5} \mathrm{SI}$, and with only one exception is much smaller than $k_{f}$ (Table 2), suggesting a predominance of magnetite rather than pyrrhotite, according to Dekkers [1988]. The ratio $k_{f} / M_{s}$ is surprisingly large, typically around 40 or $50 \mu \mathrm{m} / \mathrm{A}$ (Table 1 ). This is much larger than values calculated from published data for synthetic magnetites over a very wide range of grain sizes [e.g., Maher, 1988]. The ARM/SIRM ratio is also unusually high, ranging from $10 \%$ to over $30 \%$ (Table 2). The frequencydependence is quite strong, in many samples exceeding $10 \%$

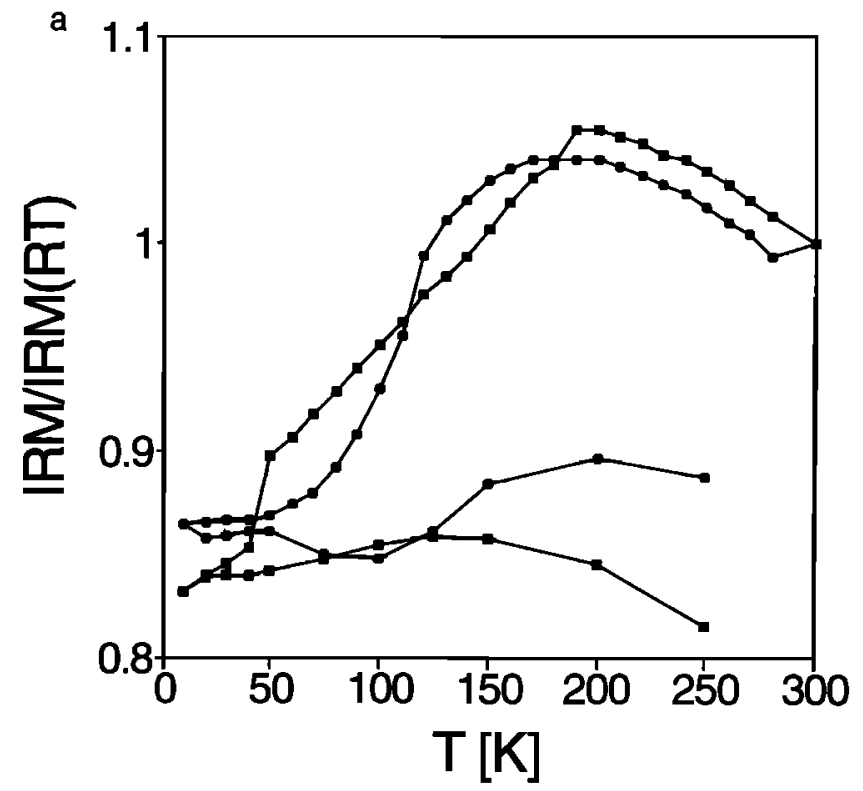

b

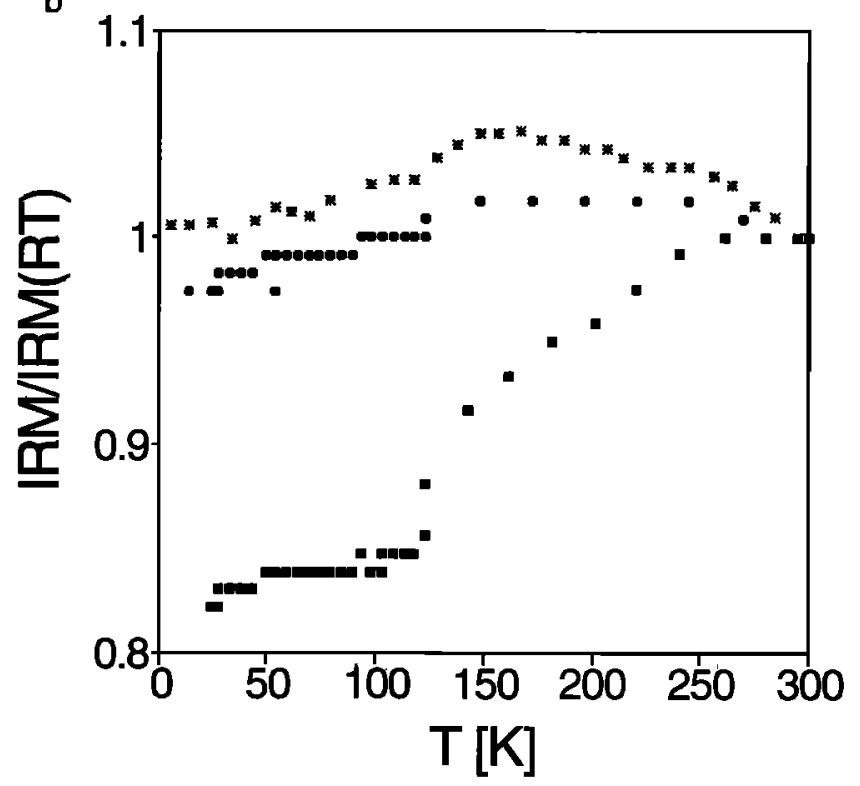

Fig. 2. Behavior of saturation remanence during zero-field cycling to liquid nitrogen temperature. (a) measured on MPMS in Minneapolis; (b) measured on SHE instrument in Grenoble. Note the behavior at the magnetite transition temperature $(120 \mathrm{~K})$ and at the pyrrhotite transition temperature $(32 \mathrm{~K})$. Also note the broad maximum for most samples between about 150 and $200 \mathrm{~K}$.

(Table 3). Susceptibilities in the Knox samples were too low to obtain consistent measurements of $k_{f d}$, but for the Trenton and Onondaga samples repeat measurements showed that $k_{f d}$ was reproducible to within $2 \%$.

\section{Discussion}

\section{Importance of Pyrrhotite}

The absence of a marked magnetic transition near $32 \mathrm{~K}$ appears to indicate that the contribution of pyrrhotite to the magnetic properties of the Trenton and Onondaga samples is negligible in 
TABLE 1. Ferromagnetic Susceptibilities and Saturation Magnetization

\begin{tabular}{|c|c|c|c|c|c|}
\hline Sample & $k_{l f}$ & $k_{p}$ & $k_{f}$ & $M_{s}$ & $k_{f} / M_{s}$ \\
\hline \multicolumn{6}{|c|}{ Trenton Limestone } \\
\hline MTA $3^{*}$ & 7.68 & 0.44 & 7.24 & 1.71 & 42.4 \\
\hline MTA 4 & 4.46 & 0.27 & 4.19 & 0.97 & 43.3 \\
\hline MTA 6 & 3.72 & 0.08 & 3.64 & 0.88 & 41.4 \\
\hline MTA $12^{*}$ & 5.64 & -0.19 & 5.83 & 0.76 & 76.9 \\
\hline \multicolumn{6}{|c|}{ Onondaga Limestone } \\
\hline $7-23$ & 2.35 & 1.10 & 1.24 & 0.37 & 33.5 \\
\hline $8-27$ & 13.19 & -0.05 & 13.24 & 2.97 & 44.6 \\
\hline $9-27$ & 7.10 & 0.73 & 6.37 & 1.46 & 43.6 \\
\hline FO10-3* & 12.71 & 2.71 & 10.00 & 2.30 & 43.5 \\
\hline FO10-6* & 8.60 & 0.45 & 8.15 & 1.60 & 51.0 \\
\hline $10-23$ & 14.14 & -0.12 & 14.26 & 2.92 & 48.8 \\
\hline $11-10$ & 1.55 & 0.50 & 1.05 & 0.42 & 25.0 \\
\hline $12-24$ & 2.48 & -0.15 & 2.63 & 0.62 & 42.4 \\
\hline $13-32$ & 0.63 & -0.04 & 0.66 & 0.25 & 26.4 \\
\hline $14-29$ & 8.46 & 8.13 & 0.33 & 0.28 & 11.8 \\
\hline \multicolumn{6}{|c|}{ Knox Dolomite } \\
\hline BAQ $2.2^{*}$ & 3.62 & 2.40 & 1.22 & 0.69 & 17.6 \\
\hline FCP $3.2^{*}$ & 2.96 & 1.17 & 1.80 & 0.55 & 39.3 \\
\hline $\mathrm{NM} 42.1^{*}$ & 4.38 & 1.24 & 3.14 & 0.78 & 28.3 \\
\hline
\end{tabular}

Units for $k$ are $10^{-5}$ SI volume-normalized; $M_{s}$ is in $\mathrm{A} / \mathrm{m}$; and $k_{f} / M_{S}$ is in $\mu \mathrm{m} / \mathrm{A}$.

* For these samples, $k_{p}$ was measured by the SHE susceptometer and $k_{o}$ by kappabridge.

For all other samples $k_{p}$ was measured with a vibrating-sample magnetometer (VSM)

and $k_{o}$ was measured with a Bartington bridge.

TABLE 2. Ferromagnetic and Anhysteretic Susceptibilities

\begin{tabular}{lcrcccc}
\hline Sample & $k_{f}$ & $k_{a}$ & $M_{r s} / H_{c r}$ & $\mathrm{ARM} / M_{r s}$ & $k_{a} / k_{f}$ & $k_{a}\left(M_{r s} / H_{c r}\right)$ \\
\hline \multicolumn{7}{c}{ Onondaga limestone } \\
FO1-8 & 4.56 & 46.6 & 0.69 & 0.24 & 10.2 & 68 \\
FO2-12 & 7.59 & 57.9 & 1.17 & 0.20 & 7.6 & 50 \\
FO3-2 & 6.06 & 49.3 & 0.86 & 0.21 & 8.1 & 57 \\
FO5-4 & 1.94 & 13.1 & 0.22 & 0.18 & 6.8 & 60 \\
FO5-7 & 1.35 & 7.4 & 0.14 & 0.12 & 5.5 & 53 \\
FO5-9 & 1.16 & 7.6 & 0.13 & 0.17 & 6.6 & 58 \\
& & & Knox Dolomite & & & \\
BAL 1.3C & 0.09 & 22.6 & 0.23 & 0.37 & 251 & 98 \\
BAQ 1.1C & 0.42 & 17.1 & 0.22 & 0.38 & 41 & 78 \\
COP 7.12 & 0.19 & 9.4 & 0.11 & 0.35 & 49 & 85 \\
FCP 3.1C & 1.18 & 25.6 & 0.36 & 0.29 & 22 & 71 \\
NM 35.1A & 0.90 & 4.8 & 0.13 & 0.15 & 5.3 & 39 \\
NM 42.3 & 1.20 & 8.7 & 0.22 & 0.16 & 7.3 & 39 \\
& & & & &
\end{tabular}

$k_{f}$ and $k_{a}$ are recalculated from data of McCabe et al. [1989]. Units for $k_{f}, k_{a}$ and $M_{r s} / H_{c r}$ are

$10^{-5}$ SI volume-normalized; the remaining ratios are dimensionless.

comparison to that of magnetite. For the Knox samples, the suggestion of a $32 \mathrm{~K}$ transition in one sample indicates that pyrrhotite may be a significant carrier of the SIRM. For all three formations, the broad peak around $200 \mathrm{~K}$ is consistent with a significant pyrrhotite contribution, as are the SIRM unblocking temperature spectra. If pyrrhotite is in fact a significant remanence carrier, the reason for the absence of a low-temperature transition requires further investigation; it is possible that unknown factors such as chemical impurities, grain size and grain shape may suppress the transition in pyrrhotite as they do in magnetite and hematite [Nininger and Schroeer, 1978; Kobayashi and Fuller, 1968]. Thus, while the absence of a clear $32 \mathrm{~K}$ transition does not 
TABLE 3. Frequency Dependence of Susceptibility

\begin{tabular}{lccr}
\hline Sample & $k_{l f}$ & $k_{h f}$ & $k_{f d}$ \\
\hline \multicolumn{4}{c}{ Trenton Limestone } \\
MTA 1Y & 7.35 & 6.65 & \\
MTA 5X & 7.40 & 6.50 & 9.5 \\
MTA 7X & 7.85 & 6.75 & 12.2 \\
MTA 8Y & 6.40 & 5.85 & 14.0 \\
MTA 8Z & 7.05 & 6.25 & 8.6 \\
MTA 10Y & 6.45 & 5.35 & 11.4 \\
MTA 13Y & 6.75 & 6.05 & 17.1 \\
MTA 15Y & 4.95 & 4.25 & 10.4 \\
MTA 16X & 7.40 & 6.35 & 14.1 \\
& Onondaga limestone & 14.2 \\
FO10-1 & 12.75 & 11.80 & \\
FO10-2 & 13.65 & 12.40 & 7.5 \\
FO10-7 & 9.25 & 8.55 & 9.2 \\
FO10-9 & 14.45 & 13.35 & 7.6 \\
& & & 7.6 \\
\hline
\end{tabular}

Units of $k_{h f}$ and $k_{l f}$ are $10^{-5}$ SI volume-normalized.

$k_{f d}=\left(k_{h f}-k_{l f}\right) / k_{l f}$, where $h f$ and $l f$ refer to high-frequency and low-frequency values respectively.

support a significant pyrrhotite contribution, it may not necessarily rule one out.

The alternative test for pyrrhotite, suggested by Dekkers [1988], appears at first to indicate resoundingly the predominance of magnetite, especially in the New York samples. The ratios $M_{r s} J H_{c r}$ are invariably much less than $k_{f}$ (Table 2); for the Knox samples $k_{f}$ is comparable to this ratio, and in one case it is smaller. Note that the Dekkers test can be restated as $k_{a}>k_{f}$ for pyrrhotite, by using the theoretical relationship $M_{r s} / H_{c r} \approx k_{a}$, where $k_{a}$ is the anhysteretic susceptibility [Dankers, 1978; Hartstra, 1982; Maher, 1988]. Rochette [1988] has also pointed out that whereas $k_{a} / k_{f}$ is generally not much larger than unity for magnetite (except for extremely fine grain sizes), it is typically 10 or more for pyrrhotite. Table 2 shows that $k_{a} / k_{f}$ is much greater than one for all of these samples, as shown previously by McCabe et al. [1989]. This is consistent with a substantial contribution from pyrrhotite, although it probably does not require one (as discussed below).

The origin of the previously observed high $\mathrm{H}_{c r} / \mathrm{H}_{c}$ ratios [Jackson, 1990a] therefore may now need to be reevaluated. The general requirement for anomalously high $H_{c r} / H_{c}$ ratios is a bimodal distribution of coercivities, with the softer phase contributing the majority of $M_{s}$, and the harder phase carrying most of $M_{r s}$ [Nagata and Carleton, 1987; Parry, 1982; Kneller, 1969]. For pyrrhotite, coexisting with magnetite, to be the cause of the anomalous hysteresis ratios in the remagnetized Paleozoic carbonates, it would have to be the principal carrier of IRM. The unblocking temperature spectra of SIRM, $k_{a} / k_{f}$ ratios, and SIRM maximum at $200 \mathrm{~K}$ appear to be consistent with this; the lack of a well-defined low-temperature transition argues against this idea but does not necessarily rule it out. The alternative test for pyrrhotite is also somewhat ambiguous: the relationship $M_{r s} J H_{c r} \ll k_{f}$ appears to rule out a significant pyrrhotite contribution in the New York samples [Dekkers, 1988], but the relation $k_{a} \gg k_{f}$ is more typical of pyrrhotite than of magnetite [Rochette, 1988].

The origin of the pyrrhotite is unlikely to be related to that of the magnetite because of the widely different geochemical environments in which these minerals form. At least some of the pyrrhotite predates Kiaman magnetite formation: Suk et al. [1991] have observed magnetite as a partial replacement of monoclinic pyrrhotite in Devonian carbonates from New York. However, it is clear that ferrimagnetic pyrrhotite does not contribute to the characteristic component of natural remanence, which unblocks above about $350^{\circ} \mathrm{C}$. It is possible that it contributes in some way to the Cenozoic NRM component, which has unblocking temperatures that are considered anomalously high for a viscous remanence in magnetite [Kent, 1985], but the mechanism by which it may have acquired such a remanence is unclear.

Perhaps the most important questions regarding the presence or absence of monoclinic pyrrhotite are (1) to what extent does it affect the unusual rock-magnetic properties of these samples, and (2) what may reasonably be inferred from the presence or absence of similar magnetic properties in other rocks? If these properties (high values for $k_{a} / k_{f}$ ARM/SIRM, $M_{r s} / M_{s}, H_{c r} / H_{c}$, etc) are controlled by the authigenic magnetite alone, they provide a fingerprint that can potentially be used to identify similar chemically remagnetized carbonate rocks in other settings. On the other hand, if the properties described above are a consequence of the coexistence of magnetite and ferrimagnetic pyrrhotite, the conclusions that may be drawn from their presence or especially from their absence are somewhat less clear.

\section{Importance of Superparamagnetic Particles}

The very high values of $k_{f} / M_{s}$ and the strong frequency dependence of susceptibility indicate an important contribution from superparamagnetic (SP) particles, which have greatly enhanced susceptibility. The specific susceptibility of stable (SD or larger) ferrimagnetic grains (per unit mass of ferrimagnetic material) has a rather weak grain size dependence. For magnetite, measured values range from about $3 \times 10^{-4}$ to $4 \times 10^{-4} \mathrm{~m}^{3} / \mathrm{kg}$ in the SD range up to about $6 \times 10^{-4}$ or $7 \times 10^{-4} \mathrm{~m}^{3} / \mathrm{kg}$ for MD particles [Dankers, 1978; Ozdemir and Banerjee, 1982; Maher, 1988]. In theory, however, the specific susceptibility of SP material may be higher than these values by an order of magnitude or more [Stephenson, 1971; Stacey and Banerjee, 1974; O'Reilly, 1984]. Maher measured specific susceptibilities up to $11 \times 10^{-4} \mathrm{~m}^{3} / \mathrm{kg}$ for synthetic magnetites in the size range below $0.03 \mu \mathrm{m}(30 \mathrm{~nm})$. Because the mass of ferrimagnetic material in natural samples is unknown, it is appropriate to normalize by the saturation magnetization. Taking a value of $92 \mathrm{Am}^{2} / \mathrm{kg}$ for the saturation magnetization of magnetite yields a ratio $k_{f} / M_{s}$ of about 5 to $8 \mu \mathrm{m} / \mathrm{A}$ for stable grain sizes (SD or larger), but it may reach 50 or more $\mu \mathrm{m} / \mathrm{A}$ for SP grains. Moskowitz et al. [1988] have reported ratios as high as $35 \mu \mathrm{m} / \mathrm{A}$ for bacterial magnetites with dimensions of 40 to $50 \mathrm{~nm}$. The high values of $k_{f} / M_{s}$ in the carbonate samples of this study, up to nearly $80 \mu \mathrm{m} / \mathrm{A}$ (Table 1), thus indicate that a very large fraction of the ferrimagnetic susceptibility comes from SP particles.

The presence of a significant SP fraction is qualitatively confirmed by the high values of $k_{f d}$ (Table $3 ; k_{f d}=\left(k_{h f^{k}}{ }_{l f}\right)^{/ k} l f$ where $h f$ and $l f$ refer to high-frequency and low-frequency values respectively). For the Trenton limestone, $k_{f d}$ is uniformly greater than $8 \%$, reaching values as high as $17 \%$. For comparison, the highest value reported by Maher [1988] was $11 \%$, for a sample containing synthetic magnetite with a mean grain size of $22 \mathrm{~nm}$. Eick [1989] has described susceptibility decreases of almost $50 \%$ (over two decades of frequency) in ash-flow tuffs containing elongate magnetites with an average length (determined by scanning and transmission electron microscope (SEM and TEM) observations) of $50 \mathrm{~nm}$ [Schlinger et al., 1991; Eick and Schlinger, 
1990]. Interestingly, however, the 40 to $50 \mathrm{~nm}$ magnetites produced by magnetotactic bacteria studied by Moskowitz et al. [1988] show no frequency dependence (B. M. Moskowitz, personal communication, 1991). For the Onondaga samples $k_{f d}$ is on average slightly lower than for the Trenton, perhaps as a consequence of a somewhat larger average contribution of (frequency-independent) paramagnetic material.

Large values of $k_{f d}$ indicate the presence of an important population of grains with blocking frequencies between 470 and $4700 \mathrm{~Hz}$, i.e., with relaxation times (at room temperature) of approximately $10^{-3} \mathrm{~s}$. Using Néel's formula relating relaxation time to volume, it is easy to calculate that these relaxation times correspond to volumes on the order of $10^{-25} \mathrm{~m}^{3}$, or diameters in the vicinity of $20 \mathrm{~nm}$. Particles in this size range are superparamagnetic at $470 \mathrm{~Hz}$ (i.e., their relaxation time is shorter than the measurement time constant) but "stable" at the higher frequency (relaxation time longer than the measurement time constant). If we assume that susceptibility in these particles drops by about a factor of 10 with the change from SP to SD state on increasing frequency [e.g., Stephenson, 1971], we can conclude that $10 \% k_{f d}$ may be generated by only about $1 \%$ of the total ferrimagnetic volume (in other words, only about $1 \%$ of the magnetite/pyrrhotite is in the size range with blocking frequencies between 470 and 4700 ). If the susceptibility drop at high frequency is less than a factor of 10 , the volume fraction of SP grains will be concomitantly larger; the high values of the ratio $k_{f} M_{s}$ suggest that this is probably the case. Values 5 to 10 times greater than the self-demagnetization limit $\left(1 /\left(N M_{s}\right) \approx 6 \mu \mathrm{m} / \mathrm{A}\right)$ suggest that as much as $90 \%$ of the susceptibility comes from SP particles; depending on their specific susceptibility, this appears to indicate that SP particles constitute somewhere around $50 \%$ of the total volume of ferrimagnetic material.

Very high ARM intensities are another characteristic of very fine grain size, near the SP-SD boundary. For these samples, the ARM acquired in an $80 \mathrm{~A} / \mathrm{m}$ DC field (1 Oe or $100 \mathrm{mT}$ equivalent) is between $15 \%$ and $35 \%$ of $M_{r s}$. Similar ARM/SIRM ratios have been reported by Moskowitz et al. [1988] for bacterial magnetite. Moskowitz et al. use these ratios to calculate interaction fields [Jaep, 1971; Banerjee and Mellema, 1974], and find that such high ratios require very weak interaction (interaction fields on the order of 0.01 to $0.05 \mathrm{mT}$, i.e., less than about half an Oersted). This is consistent with previous evidence that the particles in the remagnetized carbonates are predominantly non interacting [Jackson, 1990a].

Table 2 also shows that the theoretical approximation $k_{a} \approx M_{r s} / H_{c r}$ is grossly inaccurate for these samples, with $k_{a}$ exceeding this ratio by about a factor of 50. This relationship $\left(k_{a} \gg M_{r s} J H_{c r}\right)$ seems to be a further characteristic of ultrafine particles. Examination of the data of Maher [1988] shows that the ratio $k_{a} /\left(M_{r s} / H_{c r}\right)$ exceeds 2.0 for a few of her synthetic ultrafine-grained samples and that each of these few also exhibit $k_{f d}>5 \%$ and/or specific susceptibility exceeding $10^{-3} \mathrm{~m} / \mathrm{kg}$. In contrast, Dankers [1978] measured $k_{a}$ values very close to $M_{r s} / H_{c r}$ for relatively coarse-grained magnetites.

High values of $k_{a} /\left(M_{r s} / H_{c r}\right)$ (as well as high $k_{f d}$ and high specific susceptibility) seem to be suppressed with increasing particle interactions, inasmuch as none of these effects can be found in Maher's [1988] data for samples containing more than $0.3 \%$ magnetite by weight. The mean value of $M_{s}$ for the Paleozoic carbonates of this study is on the order of $1 \mathrm{~A} / \mathrm{m}$, corresponding to a magnetite content of a few parts per million. An absence of interaction effects may be the reason that these characteristic properties of ultrafine particles $\left(k_{f d}>5 \%\right.$, $k_{f} / M_{s}>10 \mu \mathrm{m} / \mathrm{A}, \mathbf{k}_{\mathrm{a}} \gg \mathrm{M}_{\mathrm{rs}} / \mathrm{H}_{\mathrm{cr}}$, and ARM/SIRM $\left.>10 \%\right)$ are better expressed in these carbonate samples than in Maher's samples, exclusively containing synthetic ultrafine magnetites.

\section{Origin of Bulk Magnetic Properties and Natural Remanence}

In view of these new observations, we suggest two possible causes for the wasp-waisted character of the hysteresis loops and the associated high $\mathrm{H}_{\mathrm{cr}} / \mathrm{H}_{\mathrm{c}}$ ratios that are typical of these samples [Jackson, 1990a]. The bimodality of coercivities that is required to generate such constricted loops may be provided either by a mixture of pyrrhotite and magnetite or by a mixture of SP and larger magnetites. It remains plausible that pyrrhotite contributes significantly to the observed properties, especially of some Knox samples, but the evidence is inconclusive. The strongest indications of its possible presence are the humps in SIRM cooling curves, which closely match the measured temperature dependence of $M_{S}$ in pyrrhotite [Dekkers, 1989]. Although pyrrhotite clearly does not contribute to the characteristic late Paleozoic remanence, it may play some role in the anomalous stability of the Cenozoic (presumably viscous) overprint [Kent, 1985], and may also be important in controlling ARM anisotropy [McCabe et al., 1985; Jackson et al., 1989].

In contrast to the remaining uncertainty about the importance of pyrrhotite, the evidence is quite clear for a major contribution from ultrafine magnetites, spanning the SP-SD boundary. Uncommonly high values of $k_{f} / M_{s}$ and $k_{f d}$ such as we have found have no other known source. Similarly, ARM/SIRM ratios exceeding $10 \%$ require fine SD carriers [Dunlop and West, 1969; Schmidbauer and Schembera, 1987]; further they preclude significant particle interactions [Moskowitz et al., 1988]. The presence of such material also helps to account for the low bulk coercivities and wasp-waisted hysteresis loops observed previously. In fact the hysteresis properties can be modeled very closely as a mixture of superparamagnetic and stable single-domain magnetite controlled by cubic magnetocrystalline anisotropy. The theoretical and empirical results of Kneller [1969], Parry [1982], and Nagata and Carleton [1987] indicate that the high $\mathrm{H}_{c r} / \mathrm{H}_{C}$ ratios can be accounted for if the SP fraction is responsible for the majority of $M_{S}$ (i.e., more than half of the total weight of magnetite is in the SP size range), while the remanence is carried mainly by stable SD grains. A ferrimagnetic assemblage containing $50 \%$ or more SP particles is consistent with the $k_{f} M_{s}$ ratios we have measured, as well as with the low bulk coercivities (as low as $4 \mathrm{mT}$ in many of the samples). The high $M_{r s} M_{s}$ ratio of cubic SD particles (0.87) would be reduced by mixing with an equal volume of SP material to around 0.4; this is somewhat larger than the average value found by Jackson [1990a]. Such a mixture can thus account for virtually all of the rockmagnetic observations: high ratios of $M_{r s} / M_{s}$ and $H_{c r} / H_{c}$; extremely large normalized susceptibilities $k_{f} M_{s}$ and strong frequency dependence of susceptibility; high ARM/SIRM ratios, as well as the unblocking temperature distributions for SIRM and for the Kiaman component of NRM [e.g., Saffer and $M c$ Cabe, 1992]. It is also interesting to note that the differences in hysteresis properties for the three formations are compatible with the susceptibility differences: the Knox samples have the highest $M_{r s} M_{s}$ ratios, and thus they must have the smallest SP fraction; they also have the lowest $k_{f} M_{s}$ ratios.

Although petrographic studies of magnetic extracts from remagnetized limestones have generally found a preponderance of relatively coarse-grained (larger than a few microns) magnetite [e.g., McCabe et al., 1983; Wisniowiecki et al., 1983; Bachtadse et 
al., 1987; Suk et al., 1990a, b; Lu et al., 1990], it is interesting to note that more recent studies using higher-resolution STEM techniques have led to direct observation of an additional population of much finer particles, with sizes of $200 \mathrm{~nm}$ and below [Suk et al., 1991]. Suk et al. [1991] have found that these finer magnetites occur as void coatings in calcite and dolomite, apparently indicating direct precipitation from solution, as well as replacing pyrite. It is reasonable to expect that such a process would generate a considerable amount of ultrafine-grained magnetite as well as the more readily observable larger particles. Thus the previous disparity in petrographic and rock magnetic characterizations of the magnetic particles in these rocks is beginning to be resolved. A remaining problem is the fact that petrographic observations most often seem to show magnetites occurring in polycrystalline aggregates, whereas magnetic measurements strongly indicate a lack of interaction between particles.

The remarkable magnetic properties of these rocks, like their remanence, are a direct consequence of late Paleozoic diagenesis. All of the remagnetized carbonate units investigated in this study and in the previous study of Jackson [1990a] share the following host of uncommon rock magnetic properties:

$$
\begin{gathered}
M_{r s} M_{s} \approx 0.89\left(H_{c r} / H_{c}\right)^{-0.6} \\
k_{f} M_{s} \approx 50 \mu \mathrm{m} / \mathrm{A} \\
\mathrm{ARM} / M_{r s} \approx 20 \% \\
k_{a}\left(M_{r s} H_{c r}\right) \approx 50 \\
k_{a} / k_{f} \geq 5 \\
k_{f d} \geq 5 \%
\end{gathered}
$$

Three of these (2), (3), and (6) have only been reported previously for ultrafine magnetites (a few tens of nanometers) [e.g., Moskowitz et al., 1988; Maher, 1988; Eick, 1989]. Characteristic (1) is similar to behavior reported for magnetitehematite mixtures [Jackson et al., 1990], and may reflect an important, previously-unrecognized pyrrhotite contribution. Alternatively, it may be a consequence of dominantly cubic (magnetocrystalline) anisotropy, as interpreted by Jackson [1990a]. In any case, we are unaware of any other rock or synthetic analog in which all of these properties have been found together. Therefore these appear to constitute a diagnostic set of rock magnetic criteria for recognizing chemically remagnetized carbonate rocks. Research designed to test this idea by analysis of additional remagnetized and nonremagnetized carbonates of various ages and from various locations is currently underway.

An additional point worth mentioning is that the very significant contribution of SP particles to the ferrimagnetic susceptibility renders interpretation of the anisotropy of magnetic susceptibility (AMS) highly uncertain. The conclusions of Jackson [1990b] regarding AMS in the Trenton limestone, based on the analytical method of Henry and Daly [1983], are therefore probably overstated. Figure 3 of Jackson [1990b] may be more appropriately interpreted as indicating that anisotropy in Trenton samples generally decreases with increasing mean susceptibility; this may be related to a greater proportion of SP particles in those samples.

\section{SUMMARY AND CONCLUSIONS}

Evidence for or against a significant pyrrhotite contribution to the unusual bulk magnetic properties of remagnetized Paleozoic carbonates remains somewhat equivocal. The pyrrhotite lowtemperature magnetic transition is poorly expressed in one sample of Knox dolomite and absent in all other samples tested. For the Onondaga and Trenton samples, the ferrimagnetic susceptibility is much larger than the ratio $M_{r s} / H_{c r}$ indicating a predominance of magnetite according to Dekkers [1988]; for the Knox samples the Dekkers test indicates significant pyrrhotite. For all three units, $k_{f}$ is much smaller than the anhysteretic susceptibility (often by more than an order of magnitude), which is generally characteristic of pyrrhotite according to Rochette [1988]. However $k_{a} / k_{f}$ ratios for the Onondaga and Trenton samples are comparable to those found by Moskowitz et al. [1988] for bacterial magnetites and by Maher [1988] for synthetic magnetites spanning the SP-SD boundary.

There is clear evidence for a very significant contribution of ultrafine particles to the bulk magnetic properties of all three of the stratigraphic units studied. All samples have unusually high ratios of $k_{f} d M_{s}, \mathrm{ARM} / \mathrm{SIRM}$, and $k_{a} /\left(M_{r s} / H_{c r}\right)$, as well as a strong frequency-dependence of susceptibility. The normalized susceptibility values indicate that superparamagnetic particles may constitute more than half of the total mass of ferrimagnetic material in these samples; this is consistent with previous observations of anomalous hysteresis behavior.

Acknowledgments. This work was supported by NSF grant EAR 9005075 and by CNRS. We thank Bruce Moskowitz for critically reading the manuscript, and Rich Reynolds and Guy Smith for their constructive reviews. This is IRM contribution 9107.

\section{REFERENCES}

Bachtadse, V., R. Van der Voo, F. M. Haynes, and S. E. Kesler, Late Paleozoic remagnetization of mineralized and unmineralized Ordovician carbonates from east Tennessee: Evidence for a post-ore chemical event, J. Geophys. Res., 92, 14,165-14,176, 1987.

Banerjee, S. K., and J. P. Mellema, A new method for determination of paleointensity from the ARM properties of rocks, Earth Planet. Sci. Lett., 23, 177-184, 1974.

Bin, M., and R. Pauthenet, Magnetic anisotropy in pyrrhotite, $J$. Appl. Phys., 34, 1161-1162, 1963.

Chikazumi, S., Current understanding of low-temperature phase transition of magnetite, particularly in relation to the behavior of magnetocrystalline anisotropy, Am. Inst. Phys. Conf. Proc., 13, 382-387, 1975.

Clark, D. A., Hysteresis properties of sized dispersed monoclinic pyrrhotite grains, Geophys. Res. Lett., 11, 173-176, 1984.

Dankers, P. H., Magnetic properties of dispersed natural iron oxides of known grain size, PhD thesis, Univ. of Utrecht, 1978.

Dekkers, M. J., Magnetic properties of natural pyrrhotite, Part I: Behaviour of initial susceptibility and saturation-magnetizationrelated rock-magnetic parameters in a grain-size dependent framework, Earth Planet. Sci. Lett., 52, 376-393, 1988.

Dekkers, M. J., Magnetic properties of natural pyrrhotite, Part II: High- and low-temperature behaviour of Jrs and TRM as a function of grain size, Earth Planet. Sci. Lett., 57, 266-283, 1989.

Dekkers, M. J., J.-L. Mattéi, G. Fillion, and P. Rochette, Grain-size dependence of the magnetic behavior of pyrrhotite during its low-temperature transition at 34K, Geophys. Res. Lett., 16, 855858, 1989.

Dunlop, D. J., and K. S. Argyle, Separating multidomain and single-domain-like remanences in pseudo-single-domain 
magnetites (215-540 $\mathrm{nm}$ ) by low-temperature demagnetization, J. Geophys. Res., 96, 2007-2017, 1991.

Dunlop, D. J., and G. West, An experimental evaluation of singledomain theories, Rev. Geophys., 7, 709-757, 1969.

Eick, P., Correlation of ash-flow tuffs by multifrequency measurements, M.S. thesis, Univ. of Utah, Salt Lake City, 1989.

Eick, P. and C. Schlinger, The use of magnetic susceptibility and its frequency dependence for delineation of a magnetic stratigraphy in ash-flow tuffs, Geophys. Res. Lett., 17, 783-786, 1990.

Freeman, R., Magnetic mineralogy of pelagic limestones, Geophys. J. R. Astron. Soc., 85, 433-452, 1986.

Hartstra, R. L., Grain-size dependence of initial susceptibility and saturation magnetization-related parameters of four natural magnetites in the PSD-MD range, Geophys. J. R. Astron. Soc., $71,477-495,1982$.

Henry, B., and L. Daly, From qualitative to quantitative magnetic anisotropy analysis: The prospect of finite strain calibration, Tectonophysics, 98, 327-336, 1983.

Jackson, M. J., Diagenetic sources of stable remanence in remagnetized Paleozoic cratonic carbonates: A rock magnetic study, J. Geophys. Res., 95, 2753-2762, $1990 a$.

Jackson, M. J., Magnetic anisotropy of the Trenton Limestone revisited, Geophys. Res. Lett., 17, 1121-1124, $1990 b$.

Jackson, M. J., J. P. Craddock, M. M. Ballard, R. Van der Voo, and $\mathrm{C}$. McCabe, Anhysteretic magnetic anisotropy, and calcite twin strains in Devonian carbonates from New York State, Tectonophysics, 161, 43-53, 1989.

Jackson, M., H.-U. Worm, and S. K. Banerjee, Fourier analysis of digital hysteresis data: Rock magnetic applications, Phys. Earth Planet. Inter., 65, 78-87, 1990.

Jaep, W. F., Role of interactions in magnetic tapes, J. Appl. Phys., 42, 2790-2794, 1971.

Kent, D. V., Paleomagnetism of the Devonian Onondaga limestone revisited, J. Geophys. Res., 84, 3576-3588, 1979.

Kent, D. V., Thermoviscous remagnetization in some Appalachian limestones, Geophys. Res. Lett., 12, 805-808, 1985.

King, J., S. K. Banerjee, J. Marvin, and Ö. Özdemir, A comparison of different magnetic methods for determining the relative grain size of magnetite in natural materials: some results from lake sediments, Earth Planet. Sci. Lett., 59, 404-419, 1982.

Kneller, E., Fine particle theory, in Magnetism and Metallurgy, pp. 366-472, Academic, San Diego, 1969.

Kobayashi, K., and M. Fuller, Stable remanence and memory of multidomain materials with special reference to magnetite, Philos. Mag., 18, 601-624, 1968.

Lowrie, W. and F. Heller, Magnetic properties of marine limestones, Rev. Geophys., 20, 171-192, 1982.

Lu, G., S. Marshak, and D. V. Kent, Characteristics of magnetic carriers responsible for Late Paleozoic remagnetization in carbonate strata of the midcontinent, Earth Planet. Sci. Lett., 99, 351-361, 1990.

Maher, B. A., Magnetic properties of some synthetic sub-micron magnetites, Geophys. J. Int., 94, 83-96, 1988.

McCabe, C., and R. D. Elmore, The occurrence and origin of Late Paleozoic remagnetization in the sedimentary rocks of North America, Rev. Geophys., 27, 471-494, 1989.

McCabe, C., R. Van der Voo, D. R. Peacor, C. R. Scotese, and R. Freeman, Diagenetic magnetite carries ancient yet secondary remanence in some Paleozoic sedimentary carbonates, Geology, 11, 221-223, 1983.

McCabe, C., R. Van der Voo, and M. M. Ballard, Late Paleozoic remagnetization of the Trenton Limestone, Geophys. Res. Lett., 11, 979-982, 1984.

McCabe, C., M. Jackson, and B. B. Ellwood, Magnetic anisotropy in the Trenton limestone: results of a new technique, anisotropy of anhysteretic susceptibility: Geophys. Res. Lett., 12, 333-336, 1985.

McCabe, C., M. J. Jackson, and B. Saffer, Regional patterns of magnetite authigenesis in the Appalachian Basin: Implications for the mechanism of Late Paleozoic remagnetization, $J$. Geophys. Res., 94, 10,429-10,443, 1989.

Moskowitz, B. M., R. B. Frankel, P. J. Flanders, R. P. Blakemore, and B. B. Schwartz, Magnetic properties of magnetotactic bacteria, J. Magn. Magn. Mater., 73, 273-288, 1988.

Nagata, T., and B. J. Carleton, Magnetic remanence coercivity of rocks, J. Geomagn. Geoelectr., 39, 447-461, 1987.

Nagata, T., K. Kobayashi, and M. D. Fuller, Identification of magnetite and hematite in rocks by magnetic observation at low temperature, J. Geophys. Res., 69, 2111-2120, 1964.

Nininger, R. C. and D. Schroeer, Mossbauer studies of the Morin transition in bulk and microcrystalline $\alpha-\mathrm{Fe}_{2} \mathrm{O}_{3} J$. Phys. Chem. Solids, 39, 137-144, 1978.

O'Reilly, W., Rock and Mineral Magnetism, Blackie, Glasgow, 1984.

Özdemir, Ö, and S. K. Banerjee, A preliminary magnetic study of soil samples in west-central Minnesota, Earth Planet. Sci. Lett., pp. 393-403, 1982.

Parry, L. G., Magnetization of immobilized particle dispersions with two distinct particle sizes, Phys. Earth Planet. Inter., 28, 230-241, 1982.

Potter, D. K. and A. Stephenson, Field-impressed anisotropies of magnetic susceptibility and remanence in minerals, J. Geophys. Res., 95, 15,573-15,588, 1990.

Rochette, P., La susceptibilité anisotrope des roches faiblement magnetiques: Origines et applications, thesis, Univ. Joseph Fourier, Grenoble, 1988.

Rochette, P., G. Fillion, J.-L. Mattéi, and M. J. Dekkers, Magnetic transition at 30-34 Kelvin in pyrrhotite: Insight into a widespread occurrence of this mineral in rocks, Earth Planet. Sci. Lett., 98, 319-328, 1990.

Saffer, B. and C. McCabe, Further studies of the carbonate remagnetization in the northern Appalachian Basin, J. Geophys. Res., 97, 4331-4348, 1992.

Schlinger, C., D. R. Veblen, and J. G. Rosenbaum, Magnetism and magnetic mineralogy of ash flow tuffs from Yucca Mountain, Nevada, J. Geophys. Res., 96, 6035-6052, 1991.

Schmidbauer, E., and N. Schembera, Magnetic hysteresis properties and anhysteretic remanent magnetization of spherical Fe3O4 particles in the grain size range 60-160 nm, Phys. Earth Planet. Inter., 46, 77-83, 1987.

Scotese, C. R., R. Van der Voo, and C. McCabe, Paleomagnetism of the upper Silurian and lower Devonian carbonates of New York State: Evidence for secondary magnetizations residing in magnetite, Phys. Earth Planet. Inter., 30, 385-395, 1982.

Stacey, F. D., and S. K. Banerjee, The Physical Principles of Rock Magnetism, Elsevier, New York, 1974.

Stead, R. J., and K. P. Kodama, Paleomagnetism of the Cambrian rocks of the Great Valley of east-central Pennsylvania: Fold test constraints on the age of magnetization, in Plate Reconstruction from Paleozoic Paleomagnetism, Geophys. Monograph Ser. vol. 12, edited by L. Knopoff et al., pp. 120-130, AGU, Washington, D.C., 1984.

Stephenson, A., Single domain grain distributions: A method for 
determination of single domain grain distributions, Phys. Earth Planet. Inter., 4, 353-360, 1971.

Suk, D.-W., R. Van der Voo, and D. R. Peacor, Scanning and transmission electron microscope observations of magnetite and other iron phases in Ordovician carbonates from east Tennessee, J. Geophys. Res., 95, 12,327-12,336, 1990 a.

Suk, D.-W., D. R. Peacor, and R. Van der Voo, Replacement of pyrite framboids by magnetite in limestone and implications for paleomagnetism, Nature, 345, 611-613, $1990 \mathrm{~b}$.

Suk, D.-W., D. R. Peacor, and R. Van der Voo, Single crystal, single domain to pseudosingle domain magnetite from the Michigan Basin and New York State: A possible magnetic carrier of Alleghenian remagnetization, EOS Trans. AGU, 72, 97, 1991.

Van der Voo, R., Paleomagnetism of continental North America: The craton, its margins, and the Appalachian belt, in Geophysical Framework of the Continental United States, Mem. Geol. Soc. Am., 172, 447-470, Boulder, 1989.

Verwey, E.J.W., and P. W. Haayman, Electronic conductivity and transition point in magnetite, Physica, 8, 979, 1941.
Wisniowiecki, M. J., R. Van der Voo, C. McCabe, and W. C. Kelly, A Pennsylvanian paleomagnetic pole from the mineralized late Cambrian Bonneterre formation, southeast Missouri, J. Geophys. Res., 88, 6540-6548, 1983.

Worm, H.-U., Multidomain susceptibility and anomalously strong low field dependence of induced magnetization in pyrrhotite, Phys. Earth Planet. Inter., 69, 112-118, 1991.

S. Banerjee, M. Jackson, and J. Marvin, Institute for Rock Magnetism, Department of Geology and Geophysics, University of Minnesota, Minneapolis, MN 55455.

G. Fillion, CNRS Laboratoire Louis Nél, 38041 Grenoble Cedex, France

P. Rochette, LGIT-IRIGM, BP53X, 38041 Grenoble Cedex, France.

(Received August 13, 1991;

revised March 7, 1992;

accepted May 5, 1992.) 